DEMOGRAPHIC RESEARCH

VOLUME 32, ARTICLE 29, PAGES 827-834 PUBLISHED 29 APRIL 2015

http://www.demographic-research.org/Volumes/Vol32/29/

DOI: $10.4054 /$ DemRes.2015.32.29

Formal Relationship 24

\title{
The force of mortality by life lived is the force of increment by life left in stationary populations
}

\section{Tim Riffe}

(c) 2015 Tim Riffe.

This open-access work is published under the terms of the Creative Commons Attribution NonCommercial License 2.0 Germany, which permits use, reproduction \& distribution in any medium for non-commercial purposes, provided the original author(s) and source are given credit. See http://creativecommons.org/licenses/by-nc/2.0/de/ 


\section{Table of Contents}

$1 \quad$ Relationship $\quad 827$

2 Proof $\quad 828$

$3 \quad$ History and related results $\quad 829$

$4 \quad$ Applications $\quad 831$

$5 \quad$ Acknowledgements $\quad 832$

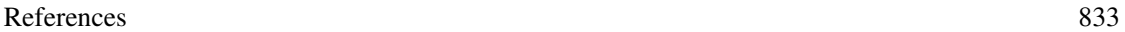




\title{
The force of mortality by life lived is the force of increment by life left in stationary populations
}

\author{
Tim Riffe ${ }^{1}$
}

\begin{abstract}
BACKGROUND

The age distribution and remaining lifespan distribution are identical in stationary populations. The life table survival function is proportional to the age distribution in stationary populations.
\end{abstract}

\section{OBJECTIVE}

We provide an alternative interpretation of the life table when viewed by remaining years of life.

\section{CONCLUSIONS}

The functions describing the mortality of birth cohorts over age are identical to the functions describing the growth of death cohorts as time to death decreases in stationary populations.

\section{Relationship}

Age can be defined as chronological, $a$ (time since birth), or thanatological, $y$ (time until death). In a stationary population, decrement over chronological age, as described by the life table, is identical to increment over thanatological age. Define the chronological force of mortality, $\mu(a)$, and the thanatological force of increment, $\mu^{\star}(y)$. We have:

$$
\mu(a)=\mu^{\star}(y) \quad \text { for } a=y \quad .
$$

\footnotetext{
${ }^{1}$ Department of Demography, University of California, Berkeley, U.S.A.
} 
Riffe: The force of mortality by life lived is the force of increment by life left in stationary populations

\section{Proof}

Chronological age structure equals thanatological age structure in a stationary population (Brouard 1989; Vaupel 2009):

$$
c(a)=g(a) \quad,
$$

where $c(a)$ is the stable chronological age structure expressed as a proportion, and $g(a)$ is the proportion of the population with $a$ remaining years of life. Using $a$ to index chronological age and $y$ to index thanatological age (time left until death), equation (2) is the same as:

$$
c(a)=c^{\star}(y) \text { for } a=y \quad,
$$

where $c^{\star}(y)$ refers to the stable thanatological age structure. $c(a)$ is proportional to the survival function, $l(a)$, which means that $c^{\star}(y)$ is proportional to some thanatological function, $l^{\star}(y)$, a stationary thanatological cumulative increment function. To untangle how this is so, it helps to be explicit about what $l(a)$ represents. A birth cohort is a group of individuals that are born at the same point in time and experience attrition over age until extinction, as described by $l(a) . l(a)$ is also the sum of all deaths to the birth cohort at ages greater than $a$, and can be thought of as the de-accumulation of the stock of future deaths over age.

$$
l(a)=\int_{0}^{\omega-a} f(a+t) d t
$$

where $f(a)$ is the life table density function, often denoted by $d(a) . f(a)$ gives the probability that a member of the birth cohort born in year $t$ will die in the year $t+a$. Since $t+a$ refers to the future, let us switch to index $y$, for thanatological age. Under stationarity, $f(y)$ is also the probability at birth that an individual born $y$ years ago will die in present year $t$. The deaths that occur together in year $t$ comprise a death cohort. In year $t-1, l(0) \cdot f(1)$ births increment to the year $t$ death cohort in the stationary population. Death cohorts grow monotonically in this way, starting with a few members that will enjoy the maximum attainable lifespan, $y=\omega$, i.e., born $\omega$ years ago in year $t-\omega$ and then expiring in year $t$. New births accumulate into a given death cohort as $y$ decreases from $\omega$ toward thanatological age 0 . From the vantage point of year $t$, we define the year $t+y$ death cohort ( $y$ years in the future), $l^{\star}(y)$ as the members born up to year $t$ that will die in exactly $y$ years.

$$
l^{\star}(y)=\int_{-(\omega-y)}^{0} f(y-t) d t
$$


Extinction of the death cohort is simultaneous upon reaching thanatological age $0, y$ years in the future. Equation (5) is equal to (4):

$$
l^{\star}(y)=\int_{-(\omega-y)}^{0} f(y-t) d t=\int_{-\omega}^{-y} f(-t) d t=\int_{y}^{\omega} f(t) d t=l(y) .
$$

The life table deaths distribution is, from this perspective, a distribution of the births to a death cohort, when read from the highest to the lowest chronological ages. The rate at which new births accumulate to death cohorts over thanatological age, $\mu^{\star}(y)$, is given by

$$
\mu^{\star}(y)=\frac{-l^{\star^{\prime}}(y)}{l^{\star}(y)},
$$

and since $l(a)=l^{\star}(y)$ for $a=y$,

$$
\begin{aligned}
& =\frac{-l^{\prime}(a)}{l(a)} \\
& =\mu(a) .
\end{aligned}
$$

The rate of birth accumulation into death cohorts over thanatological age, $\mu^{\star}(y)$, is equal to the rate of attrition of birth cohorts over chronological age, $\mu(a)$ in stationary populations. The stock of deaths in the future for chronological age $a, l(a)$, is symmetrically a description of births in the past, when structured by thanatological age, $l^{\star}(y)$. The remaining life table columns are subject to similar reinterpretations when viewed under thanatological age.

\section{History and related results}

The main contribution of this relationship is to point out the symmetry of chronological decrement and thanatological renewal processes in the case of stationary populations. The term "thanatological age" has not previously appeared in the literature, and was coined by Kenneth Wachter sometime prior to 2001. Thanatos was the Greek god of death, which is used as the reference point for age from this perspective. Explicit decompositions of chronological age groups into remaining lifespan classes is, to our knowledge, only found in Brouard (1986), who redistributed population pyramids by remaining years of life, and Miller (2001), who examined medicare expenditure as a function of time until death using the same lifetable identities. Equivalence of chronological and thanatological age structures in stationarity, also known as Carey's equality, is proven by Brouard (1989) 
Riffe: The force of mortality by life lived is the force of increment by life left in stationary populations

and again in Vaupel (2009) $)^{2}$. This latter paper and Goldstein (2012) describe more of the lineage of the result presented here.

The estimation of remaining lifespan has motivated demography since the invention of the life table, but this notion is typically dealt with as a mean (expectancy). Agespecific remaining lifespan distributions are not often used to explicitly decompose demographic quantities, such as population counts. Using the above identities, one may estimate the total population with $y$ remaining years of life, $P(y)$ directly

$$
P(y)=\int_{0}^{\infty} P(a) \mu(a+y) \frac{l(a+y)}{l(a)} d a,
$$

as Brouard (1986) did, and so approximate a population's thanatological age structure according to some mortality assumptions. This result differs from that of the more common approach of summing the population within age classes bounded by some values interpolated along the remaining life expectancy function (e.g., Sanderson and Scherbov 2005, 2007, 2010, who follow the line of Hersch 1944 and Ryder 1975).

In the present case of a stationary population, one decomposes back to birth cohorts in much the same way as is evident from (9). The probability of a member of death cohort $y^{\prime}$ being born $a^{\prime}$ years ago is equal to the probability that a member of birth cohort $a$ will die $y$ years in the future when $a=y^{\prime}$ and $y=a^{\prime}$.

$$
\begin{aligned}
f(y \mid a) & =f\left(a^{\prime} \mid y^{\prime}\right) \quad \text { for } a=y^{\prime}, y=a^{\prime} \\
& =\mu(a+y) \frac{l(a+y)}{l(a)} \\
& =\mu^{\star}\left(a^{\prime}+y^{\prime}\right) \frac{l^{\star}\left(a^{\prime}+y^{\prime}\right)}{l^{\star}\left(y^{\prime}\right)}
\end{aligned}
$$

Equation (12) seems redundant, but is less obvious when put into words: The probability of dying $y$ years in the future given survival to chronological age $a$ is the probability of surviving to chronological age $a+y$ given survival to age $a$ times the force of mortality at age $a+y, \mu(a+y)$. Viewed thanatologically, the probability of having been born $a^{\prime}$ years in the past given that one has $y^{\prime}$ remaining years of life is equal to the probability of someone in the $y^{\prime}$ death cohort being born more than $a^{\prime}$ years ago given that they have already been born times the force of increment at thanatological age $a^{\prime}+y^{\prime}, \mu^{\star}\left(a^{\prime}+y^{\prime}\right)$.

Similarly, taking $f(y \mid a)$ as the conditional density of remaining lifespans, one may calculate the variance of age-specific remaining life spans (thanatological age), where $e(a)$ is remaining life expectancy at age $a$ :

\footnotetext{
${ }^{2}$ Vaupel (2009) added detail to the more summary result reported in Goldstein (2009), which showed that the mean (or total) remaining lifespan is equal to mean (or total) life lived in the stationary population.
} 


$$
e(a)=\frac{\int_{0}^{\infty} l(a+y) d y}{l(a)}
$$

The variance of $y$ given survival to age $a$ is

$$
\sigma^{2}(y \mid a)=\int_{0}^{\infty}(e(a)-y)^{2} f(y \mid a) d y \quad,
$$

and this function will have some non-monotonic pattern over age (in human populations) that remains to be explored. ${ }^{3}$ In the reliability literature, $\sigma^{2}(y \mid a)$ is called the variance residual life function (VRLF), and its properties have been described for various common distributions (see for example Gupta 2006).

The thanatological age perspective only offers the kind of profile symmetry presented in this paper for the theoretical case of stationary populations. For changing populations, the chronological and thanatological age perspectives typically offer different profiles of the same phenomena, due to changes in lifespan distributions and fluctuations in the birth flow, and therefore offer complementary information on population structure.

\section{Applications}

Thanatological age structure can be applied to stable populations (subject to a growth rate, $r$ ), though we leave the description of a thanatological renewal model for future work. Thanatological age equates individuals that share a common terminal state rather than a common origin state. In the present relationship, this is the absorbing state of death, but the method generalizes to any terminal state or lifecourse transition that can be modeled using lifetable techniques. Potential area applications that may gain insights using such remaining-time methods include morbidity, disability, late-life savings and investment behavior, or perhaps time to birth, menopause, retirement, or graduation. Glacial or open ice pack, old growth forest, and prison populations are other examples of aggregates for which remaining time structure is inherently of equal or greater interest than time passed. Populations of fixed or controlled size, or where entries are largely a function of exits are also prime candidates for analysis using a variant of thanatological age. Examples of such populations include professional athletes in leagues, tenured professors, company directors, and vehicle fleets.

As a specific example, the question of morbidity compression has often been posed as a matter of comparing age of onset with remaining life expectancy (e.g., Fries 2002, 2003). ${ }^{4}$ In retrospect (within death cohorts), one can analytically separate between

\footnotetext{
3 This definiton works out to be the same as Chiang (1984), Chapter 10, Equation 6.10.

${ }^{4}$ In the health literature, one often sees $e(65)$ compared with average disability levels above age 65 .
} 
Riffe: The force of mortality by life lived is the force of increment by life left in stationary populations

changes in lifespan and changes in morbidity as a function of time until death. Crosstabulations of morbidity by chronological and thanatological age for two birth cohorts would allow the researcher to estimate changes in the morbidity profile over time, free from distortion due to changes in the lifespan distribution, and so directly settle the question of morbidity compression.

\section{Acknowledgements}

A big thank you to three anonymous reviewers for providing helpful suggestions, comments, and corrections. This work was supported by the National Institute On Aging of the U.S. National Institutes of Health (NIH) under Award Numbers R01-AG011552 and R01-AG040245. The content is solely the responsibility of the author and does not necessarily represent the official views of the NIH. 


\section{References}

Brouard, N. (1986). Structure et dynamique des populations. La pyramide des années à vivre, aspects nationaux et exemples régionaux. Espace, populations, sociétés 4(2): 157-168. doi:10.3406/espos.1986.1120.

Brouard, N. (1989). Mouvements et Modèles de Population. Yaoundé, Cameroun: Institut de Formation et de Recherche Démographiques.

Chiang, C.L. (1984). The Life Table and Its Applications. Malabar, FL: Robert E. Krieger.

Fries, J.F. (2002). Aging, natural death, and the compression of morbidity. Bulletin of the World Health Organization 80(3): 245-250.

Fries, J.F. (2003). Measuring and Monitoring Success in Compressing Morbidity. Annals of Internal Medicine 139(5_Part_2): 455-459. doi:10.7326/0003-4819-139-5_Part_2200309021-00015.

Goldstein, J.R. (2009). Life lived equals life left in stationary populations. Demographic Research 20(2): 3-6. doi:10.4054/DemRes.2009.20.2.

Goldstein, J.R. (2012). Historical Addendum to "Life lived equals life left in stationary populations". Demographic Research 26(7): 167-172. doi:10.4054/DemRes.2012. 26.7.

Gupta, R.C. (2006). Variance residual life function in reliability studies. Metron 54: 343-345.

Hersch, L. (1944). De la démographie actuelle à la démographie potentielle. Genève: Georg.

Miller, T. (2001). Increasing longevity and medicare expenditures. Demography 38(2): 215-226. doi:10.1353/dem.2001.0018.

Ryder, N.B. (1975). Notes on Stationary Populations. Population Index 41(1): 3-28. doi: $10.2307 / 2734140$.

Sanderson, W.C. and Scherbov, S. (2005). Average remaining lifetimes can increase as human populations age. Nature 435(7043): 811-813. doi:10.1038/nature03593.

Sanderson, W.C. and Scherbov, S. (2007). A new perspective on population aging. Demographic Research 16(2): 27-58. doi:10.4054/DemRes.2007.16.2.

Sanderson, W.C. and Scherbov, S. (2010). Remeasuring Aging. Science 329(5997): 1287-1288. doi:10.1126/science.1193647.

Vaupel, J.W. (2009). Life lived and left: Carey's equality. Demographic Research 20(3): 7-10. doi:10.4054/DemRes.2009.20.3. 
Riffe: The force of mortality by life lived is the force of increment by life left in stationary populations 